Orbis Tertius

ISSN: $1851-7811$

publicaciones@fahce.unlp.edu.ar

Universidad Nacional de La Plata

Argentina

\title{
La buena lectura. Operaciones didácticas en Ficciones
}

Fernández, Álvaro

La buena lectura. Operaciones didácticas en Ficciones

Orbis Tertius, vol. 25, núm. 31, 2020

Universidad Nacional de La Plata, Argentina

DOI: https://doi.org/10.24215/18517811e147

Atribución no comercial compartir igual (CC BY-NC-SA) 4.0 
Artículos

\section{La buena lectura. Operaciones didácticas en Ficciones}

\author{
The Good Reading. Didactic Operations in Ficciones \\ Álvaro Fernández \\ Queens College. City University of New York, Estados \\ Unidos \\ alvaro.fernandez@qc.cuny.edu
}

DOI: https://doi.org/10.24215/18517811e147

Recepción: 31 Julio 2019

Aprobación: 30 Marzo 2020

Recepción: 31 Julio 2019

Aprobación: 30 Marzo 2020

\section{Resumen:}

Jorge Luis Borges hace uso de la lógica del género policial para producir complejos textos que requieren de un lector activo. Un análisis de las metodologías de lectura que se ponen en escena en Ficciones permite pensar al libro como un productivo manual, en el sentido didáctico del término. Ficciones, como libro de lectura, plantea una teoría y una práctica que entrenan al lector en la lectura suspicaz para situarlo espectacularmente en el lugar central del hecho literario.

Palabras ClaVe: Literatura argentina, Borges, Ficciones, Didáctica, Lectura.

\section{Abstract:}

Jorge Luis Borges uses the laws of detective novels to design complex works that need to an active reader. The analysis of the reading methodologies outlined in Ficciones allows us to think the volume as a reading book, in the didactical sense of the term. As a reader, the book presents a theory and a practice on suspicious reading strategies that place the reader at the core of literature.

KEYWORDS: Argentine Literature, Borges, Ficciones, Didactics, Reading.

En una de sus clases de Introducción a la literatura, Enrique Pezzoni hace referencia a la posible función didáctica de la obra de Borges, y señala con picardía que cualquier referencia a este aspecto de sus escritos probablemente habría enfurecido al autor (Louis, 1999, p. 95). La clase explora la impresionante intención subversiva que subyace en textos que aparentemente hablan de otra cosa. Borges, antes que dar lecciones y predicar, se dedica meticulosamente a poner en crisis, a minar, a sitiar con paradojas los saberes establecidos no sólo de la literatura sino del pensamiento occidental. En ese gesto radicalmente desestabilizante, Pezzoni encuentra implícita una productiva potencia que, a su juicio, Borges se negaría a reconocer.

Pero en realidad, los textos son didácticos. ¿Por qué? Porque destruyen todos los marcos epistemológicos, destruyen los discursos del poder - vuelvo a insistir- en un caso como manipulación agresiva de las técnicas narrativas, de las escrituras narrativas tradicionales; en otro caso, por exhibición de actitudes epistemológicas. Destruyen para instruir en una forma de actividad y lectura [...]. Destruyen para instruir acerca de la transitoriedad de la supuesta estabilidad de los sistemas epistemológicos [...]. En este sentido, los textos son subversivos y didácticos a la vez (Louis, 1999, p. 95).

Los lectores que -como Pezzoni- prestan atención a esta potencialidad subversiva en Borges, suelen desembocar en descripciones fervorosas y desmesuradas, poco frecuentes en la crítica teóricamente sólida. Críticos como Pezzoni, Panesi, Ludmer, Sarlo o Pauls, formados en el estructuralismo y el post-estructuralismo - nada proclives a construir los monumentos de Autor que frecuenta la academia tradicional- hablan de los efectos de los textos de Borges como si dieran cuenta de un hecho sobrenatural que provoca estupor y zozobra. ${ }^{1}$ Efectivamente, los breves cuentos funcionan como precisos e hipnóticos mecanismos de relojería que buscan activamente superar los límites del texto y producir efectos concretos en el acto de lectura, al punto de que cuando se los lee de determinada manera, el lector puede comprobar que 
algo sucede. ${ }^{2}$ Desde esta perspectiva se vuelve especialmente interesante explorar la observación de Pezzoni y exponer la didáctica que pueden contener estos textos inquietantes y subversivos.

\section{DiDÁCTICA DE LA SOSPECHA}

A lo largo de Ficciones se dibuja la imagen de un lector deseado, capaz de leer otra cosa, de encontrar en la superficie del texto pistas que son invisibles para la mayoría y, a partir de ellas, descubrir una trama alternativa a la que se expone abiertamente. ${ }^{3}$ Esa forma de leer, activa y perspicaz, puede asociarse a la que suponen los relatos policiales de enigma, que establecen un desafío entre autor y lector que se dirime en la lectura. El género policial exige una aproximación al texto no sólo analítica sino también suspicaz: las reglas del juego habilitan la utilización de todo tipo de falsas pistas para esconder una trama que quien acepta el desafío espera develar antes de que se la expliquen. Borges aprovecha esta convención literaria de un género considerado menor para superar sus límites y, a través de la lógica del enigma, plantearle problemas centrales de filosofía y teoría literaria a un lector reflexivo y atento (Parodi, 1999, p. 78). ${ }^{4}$ Más allá de las vueltas de tuerca que puedan dársele a las leyes del género, lo que no cambia es el desafío implícito en la lectura, y es precisamente eso lo que Borges aprovecha para producir sus pequeñas piezas de relojería bajo la forma del policial: "Ya que el lector de nuestro tiempo es también un crítico, un hombre que conoce, y prevé, los artificios literarios, el cuento deberá constar de dos argumentos; uno, falso, que vagamente se indica, y otro, el auténtico, que se mantendrá en secreto hasta el fin" (2016, p. 234).

Hay dos maneras de entender la última frase: la convención del policial de enigma prescribe que al final del texto se expongan sus secretos y se saque a la luz la verdad oculta. En Borges, en cambio, la estructura del género se complejiza, y es posible que la verdadera trama de sus cuentos permanezca en secreto hasta el fin, es decir, que no se explicite nunca y sea el lector activo quien deba encontrarla por sí mismo. La gran trama de conexiones que los relatos desencadenan tiene distintos grados de visibilidad, algunas relaciones son más evidentes, otras permanecen ocultas para que un lector dedicado decida sacarlas a la luz. Si bien los cuentos cumplen con las reglas del género y al final ofrecen la solución de un enigma, al mismo tiempo abren la puerta a una infinidad de juegos asociativos para los lectores desconfiados que quieran leer otra cosa. Este diseño que puede graficarse con exóticas formas del vértigo (laberintos, cajas chinas, muñecas rusas), aparece claramente expuesto en el libro en distintos proyectos de escritura cifrada. Ficciones pone en escena las peripecias de lectores que ejercen una buena lectura, que es la que activamente desconfía de las explicaciones llanas, la que con suspicacia lee varias veces para ir más allá de la superficie del texto y develar sus múltiples niveles y dimensiones. ${ }^{5}$ Como un libro de lecturas el volumen exhibe repetidamente distintas imágenes de lectores sagaces que consiguen develar un misterio con sólo leer bien lo que hasta ese momento se había entendido de otra manera. Si estas representaciones se toman como una alusión al acto de leer Ficciones y, en consecuencia, como una interpelación al lector; asoma entonces una posible intencionalidad didáctica. El libro invita a imitar estos ejercicios y se constituye, así, como un libro de lectura en un sentido escolar, con lecciones y prácticas que enseñan a leer más allá de lo aparente. Desde esa perspectiva, "Tema del traidor y del héroe" puede considerarse como una productiva área de ejercicios para que el lector ponga a prueba las lecciones expuestas a lo largo del volumen.

Desde el comienzo, el cuento se plantea como una obra en proceso, un tema que el narrador -identificado con el autor- todavía no ha decidido concluir. Luego de barajar distintas posibilidades decide, "para comodidad narrativa", situar la acción en Irlanda, en 1824. A continuación, se expone sumariamente el argumento imaginado, que sigue la forma clásica del relato policial à la Borges: Ryan -el que será el narrador del cuento cuando tenga forma definitiva- encuentra en la narrativa de los textos de Historia, una trama oculta allí donde nadie la ha visto nunca. Baraja soluciones posibles, encuentra la respuesta al enigma y toma conciencia de que todo su descubrimiento había sido previsto por el Autor de una conspiración secreta. El 
hallazgo funciona como una violenta interpelación que lo hace sentirse como el personaje de un argumento escrito por otro.

La imagen de Ryan podría pensarse como la del lector perspicaz deseado por los textos de Borges; y su investigación, como el modelo a seguir para leer más allá de lo evidente y lograr la espectacular conexión entre autor y lector idealizada repetidamente a lo largo del libro. Sin embargo, la dimensión didáctica del cuento no se limita a la representación de una forma de leer modélica y eficaz. El cuento contiene -para el lector que quiera poner en práctica las enseñanzas de Ficciones - una potente red de conexiones ocultas que se abren en nuevas tramas y sentidos que proyectan espectacularmente la experiencia de lectura mucho más allá de las relaciones intratextuales y la representación de una vistosa figura metaliteraria.

\section{EJERCICIOS DE LECTURA}

El cuento plantea un problema que se concibe y resuelve en el mundo de los libros, un enigma que, al ser resuelto a través de una lectura metódica, consolida una íntima e idealizada relación entre el lector y el autor. ${ }^{6}$ Ryan, como un buen crítico, leyó con cuidado y detectó familiaridades, paralelos y, finalmente, asombrosas coincidencias entre dos sucesos históricos distanciados en tiempo y espacio. Gracias a su talento para leer con detalle, el investigador irlandés descubre con asombro que parte de la mitificada historia de su país -y de su familia- parece repetir la de Julio César, y se abisma en especulaciones sobre la secreta forma del tiempo. Otras revelaciones complican aún más el problema:

De esos laberintos circulares lo salva una curiosa comprobación, una comprobación que luego lo abisma en otros laberintos más inextricables y heterogéneos: ciertas palabras de un mendigo que conversó con Fergus Kilpatrick el día de su muerte, fueron prefiguradas por Shakespeare, en la tragedia de Macbeth. Que la historia hubiera copiado a la historia ya era suficientemente pasmoso; que la historia copie a la literatura es inconcebible... (Borges, 1974, p. 497)

Sus disquisiciones sobre la secreta forma del tiempo se desvían a otro campo de estudios también complejo: la relación entre realidad y representación. En la escueta exposición del tema, nada se dice sobre las conclusiones a las que llega Ryan en estas áreas del pensamiento, ya que finalmente la explicación es menos compleja que cualquier hipótesis sobre el tiempo cíclico, la estructura del universo o la posible influencia de las representaciones escritas en el mundo real: en el pasado, un hombre -Nolan- se vio obligado a ejecutar al jefe del grupo independentista al que pertenecía y para que su muerte sirviera al bien de la causa, diseñó una serie de episodios que quedarían en la memoria del país y ayudarían a forjar un heroico relato nacionalista. Para elaborar la trama de los hechos, recurrió a la ayuda de la literatura: "Nolan, urgido por el tiempo, no supo íntegramente inventar las circunstancias de la múltiple ejecución; tuvo que plagiar a otro dramaturgo, al enemigo inglés William Shakespeare" (Borges, 1974, p. 498). Ryan descubre a Nolan y lo identifica como el Autor de una Obra mayúscula, aunque invisible como tal, ya que permanece en la memoria apasionada de Irlanda transfigurada como Historia. Cuando descubre la trama, Ryan deduce el método de escritura utilizado por el autor y, también, su intencionalidad: la de señalarlo como el lector elegido para entenderlo todo en el futuro.

En la obra de Nolan, los pasajes imitados de Shakespeare son los menos dramáticos; Ryan sospecha que el autor los intercaló para que una persona, en el porvenir, diera con la verdad. Comprende que él también forma parte de la trama de Nolan... Al cabo de tenaces cavilaciones, resuelve silenciar el descubrimiento. Publica un libro dedicado a la gloria del héroe; también eso, tal vez, estaba previsto (1974, p. 498).

Luego de leer el cuento, un lector interesado en sus derivaciones teóricas puede participar del asombro por la forma cíclica del tiempo, disfrutar o sufrir la anécdota que cuestiona la validez de los mitos nacionalistas, reflexionar sobre la decisión final de ocultar el hallazgo detrás de un libro previsible, e incluso considerar también las relaciones entre la realidad y su registro escrito -la historia, en su dimensión literaria-; problemas todos que lo conducen a interesantes y muy actuales discusiones de las ciencias sociales. El brevísimo relato, así 
entendido, contiene una asombrosa multiplicidad de lecturas productivas que incluyen una somera didáctica de la lectura e interpretación de citas para desentrañar un enigma.

Sin embargo, es también posible dar un paso más, salir del mundo representado por el texto y acceder a otro nivel, a la dimensión interactiva de Ficciones. El lector, como un crítico literario, puede pensar que “Tema..." no sólo expone un argumento estructurado a través de paradójicas repeticiones y predica una técnica sofisticada de lectura y escritura, sino que también está hablando de sí mismo. ${ }^{7}$ Si se relee el cuento con suma desconfianza, con la íntima sospecha de que algo hay ahí que puede salir a la luz si se aplica la misma técnica de lectura utilizada por Ryan, la que el texto expone ostentosamente como la forma de codificar y decodificar un enigma; entonces otro círculo de repeticiones se abre y el lector queda incluido en él para descubrir, finalmente, una trama prevista por Borges. Así como Ryan descubre a Nolan en los pasajes menos dramáticos copiados de Shakespeare que usó para que su Obra asomara apenas en el discurso de la Historia, el lector de Ficciones puede encontrar las referencias de otro texto canónico utilizado por Borges para construir su tema. La dimensión interactiva le permite al lector tomar el cuento como un manual de instrucciones para hacer lo que hizo el protagonista, para experimentar su asombro ante la perfección del enigma que fue diseñado para él, para ser Ryan.

\section{TEMA DEL TRAIDOR Y DEL HÉROE}

Didácticamente, Ficciones ofrece en otro relato una pista evidente que llamará la atención del lector atento. "Tres versiones de Judas" describe las suspicaces lecturas de un personaje, que lo llevan a descubrir lo que nadie pudo en un libro famoso para entender finalmente que alguien previó su lectura, alguien que lo señala entre todos los lectores como el elegido para decodificar un enigma que, en virtud de ese reconocimiento mutuo, deberá dejar en las sombras. ${ }^{8}$ Así como Ryan opera una lectura en clave policial de la historia de Irlanda, Runeberg lee con especial suspicacia la trama de la Biblia, como si se tratara de un texto que esconde un enigma, como un apasionado teólogo, un audaz heresiarca, o el prolijo lector de una novela policial.

De Quincey especuló que Judas entregó a Jesucristo para forzarlo a declarar su divinidad y a encender una vasta rebelión contra el yugo de Roma; Runeberg sugiere una vindicación de índole metafísica. Hábilmente, empieza por destacar la superfluidad del acto de Judas. Observa (como Robertson) que para identificar a un maestro que diariamente predicaba en la sinagoga y que obraba milagros ante concursos de miles de hombres, no se requiere la traición de un apóstol. Ello, sin embargo, ocurrió. Suponer un error en la Escritura es intolerable; no menos intolerable es admitir un hecho casual en el más precioso acontecimiento de la historia del mundo. Ergo, la traición de Judas no fue casual; fue un hecho prefijado que tiene su lugar misterioso en la economía de la redención (1974, p. 515).

A través de la imagen de la exhaustiva y atenta lectura de una escritura sagrada, el relato reivindica la estrategia de decodificación suspicaz que se expone a lo largo de Ficciones como modélica para develar sentidos ocultos. En su interpretación de la Biblia, Runeberg considera las partes del relato en función de la economía de la redención, así como los formalistas rusos piensan en la economía del texto como principio organizador tanto para escribir como para leer e interpretar la literatura. ${ }^{9}$ Su análisis de la trama del episodio de la traición de Judas lo lleva a considerar hipótesis aparentemente descabelladas para los teólogos, pero consistentes en la interpretación de las Escrituras como una novela de enigma que esconde un significado ulterior que se les ha escapado a millones de devotos lectores. A partir de la lógica que establece el Libro -Dios es perfecto y absoluto, es incapaz de dobleces, medias tintas y tibiezas; cuando se hace hombre para humillarse, lo hace de forma absoluta...-, la conclusión sobre la encarnación divina es evidente, diáfana y espantosa:

Dios totalmente se hizo hombre hasta la infamia, hombre hasta la reprobación y el abismo. Para salvarnos, pudo elegir cualquiera de los destinos que traman la perpleja red de la historia; pudo ser Alejandro o Pitágoras o Rurik o Jesús; eligió un ínfimo destino: fue Judas (1974, p. 517). 
La relectura atenta, creativa y transgresora de un clásico universal ofrece una alternativa incómoda y punzante: el histórico traidor, el Traidor por excelencia cuyo nombre es figura del concepto mismo de la traición; es en realidad un héroe secreto, el verdadero hijo de Dios hecho hombre. El lector atento encontrará en "Tres versiones de Judas" no sólo ecos de "Tema del traidor y del héroe", sino una apasionante reescritura que aplica el mismo tema en la lectura y análisis de un libro sagrado. Los dos cuentos son, en cierta manera, el mismo, ya que plantean la confluencia de opuestos como heroísmo y traición en una sola persona, la fascinante imagen de un acto histórico célebre concebido de antemano como un drama destinado a impactar en la memoria colectiva de los pueblos y, más literalmente, las conexiones puntuales que unen los últimos momentos de personajes centrales como César, Kilpatrick... y Jesucristo.

El lector curioso que luego de leer "Tres versiones de Judas" vuelva a "Tema del traidor y del héroe" para reconsiderar el cuento, verá las primeras hipótesis sobre el diseño circular del tiempo -desechadas por Ryan cuando descubrió a Nolan- con otros ojos:

\footnotetext{
Otras facetas del enigma inquietan a Ryan. Son de carácter cíclico: parecen repetir o combinar hechos de remotas regiones, de remotas edades. Así, nadie ignora que los esbirros que examinaron el cadáver del héroe hallaron una carta cerrada que le advertía el riesgo de concurrir al teatro, esa noche; también Julio César, al encaminarse al lugar donde lo aguardaban los puñales de sus amigos, recibió un memorial que no llegó a leer, en que iba declarada la traición, con los nombres de los traidores (1974, p. 496-97).
}

Una relectura de "Tema..." que tenga en mente el nuevo círculo que incluye a Jesucristo, y que aplique la metodología utilizada por Ryan para resolver el enigma, encontrará en la superficie textual -en los pasajes menos dramáticos, en descripciones aparentemente innecesarias- las referencias a la Obra famosa de la que proviene originalmente el tema que se repite en Julio César y luego en la historia de Irlanda manufacturada por Nolan. La descripción del héroe es elocuente: Kilpatrick es el héroe joven "cuyo sepulcro fue misteriosamente violado" que "a semejanza de Moisés que, desde la tierra de Moab, divisó y no pudo pisar la tierra prometida" y que muere para "redimirse" (Borges 1974, p. 496). Las resonancias de la Biblia en el cuento se refuerzan al describir la Pasión del héroe: "Kilpatrick fue ultimado en un teatro, pero de teatro hizo también la entera ciudad y los actores fueron legión [...]. El condenado entró en Dublín, discutió, obró, rezó, pronunció palabras patéticas" (Borges, 1974, p. 498). ${ }^{10}$ Así como Nolan sembró su historia de sutiles citas de Shakespeare para que un lector en el futuro las descubriera, Borges narra el "Tema..." utilizando evidentes referencias a la Biblia para deslizar la existencia de otro círculo de repeticiones que se subraya en “Tres versiones de Judas". El lector atento encuentra que el cuento expone deliberadamente en el párrafo final una tecnología de lectura que, de aplicarse sobre el mismo texto, devela un enigma cifrado de forma similar al que el relato describe. Es evidente que este descubrimiento, como el de Ryan, estaba previsto, que el autor del cuento incluyó un nivel más en el diseño de repeticiones, que sale a la luz si se pone en práctica la lección que el texto propone para codificar y decodificar enigmas en los relatos épicos del pasado. La referencia a Jesucristo, sin embargo, no es la única pista que sugiere que la solución al enigma de la muerte de Kilpatrick no termina en la trama irlandesa, y que Ryan no resolvió todo el enigma.

\section{ENTRE NOSOTROS}

Al comienzo de la investigación, la serie de coincidencias entre los asesinatos de Kilpatrick y de Julio César llevan a Ryan a considerar un enigma de proporciones universales:

Esos paralelismos (y otros) de la historia de César y de la historia de un conspirador irlandés inducen a Ryan a suponer una secreta forma del tiempo, un dibujo de líneas que se repiten. Piensa en la historia decimal que ideó Condorcet; en las morfologías que propusieron Hegel, Spengler y Vico; en los hombres de Hesíodo, que degeneran desde el oro hasta el hierro. Piensa en la transmigración de las almas, doctrina que da horror a las letras célticas y que el propio César atribuyó a los druidas británicos; piensa que antes de ser Fergus Kilpatrick, Fergus Kilpatrick fue Julio César (Borges, 1974, p. 497). 
De esos laberintos circulares lo distrae el descubrimiento del sistema de citas de Shakespeare, que lo lleva a comprobar que las duplicaciones en la historia de Kilpatrick tenían origen literario. La trama del cuento se focaliza entonces en las tareas de Ryan hasta que descubre el enigma. A partir de ahí, el relato abandona al investigador y da cuenta de los alcances de la conspiración concebida por Nolan para que la muerte del traidor y del héroe quedara grabada en la ardiente memoria nacionalista de la patria. El texto se centra en el plan y se cierra con la muerte de Kilpatrick.

Así fue desplegándose en el tiempo el populoso drama, hasta que el 6 de agosto de 1824, en un palco de funerarias cortinas que prefiguraba el de Lincoln, un balazo anhelado entró en el pecho del traidor y del héroe, que apenas pudo articular, entre dos efusiones de brusca sangre, algunas palabras previstas (1974, p. 498).

La primera versión del cuento terminaba así, con la imagen del icónico asesinato destinado a forjar la memoria nacionalista de Irlanda, caracterizado como una representación teatral. ${ }^{11}$ La mención del palco -que aparenta ser una comparación que no tendría proyecciones ulteriores, ya que no se reflexiona sobre ella- obliga al lector atento a reconsiderar todo el relato. En un comentario lateral que parece sólo dar color al efectivo final del texto, se sugiere que un tema -el que se consigna en el título del cuento- vuelve recurrentemente como un arquetipo que modela la Historia. La muerte de Kilpatrick repite la de Julio César porque Nolan así lo decidió, pero también anticipa de forma inquietante el asesinato de Abraham Lincoln, que sucederá cuarenta años más tarde en Washington, un episodio que el traductor inglés no podría -según el cuento- prever. El narrador deja caer taimadamente esta observación sin subrayarla, a pesar de su peso significativo.

La mención de Lincoln funciona económicamente dentro del relato para instalar la sospecha de que la Historia presenta recurrencias sospechosas en la construcción de sus héroes, para insinuar que, al resolver un enigma, Ryan había dejado de ver otro. Su imagen de lector privilegiado capaz de resolver los enigmas ocultos en un texto se devalúa para instalar otra instancia de lectura que la supera, la del lector inquieto que lee con atención un cuento y no se conforma con la solución que provee el detective, que en definitiva no es más que un personaje que funciona en la maquinaria precisa diseñada por el autor. Esta perspectiva sobre el género policial está expuesta claramente en "Examen de la obra de Herbert Quain":

Hay un indescifrable asesinato en las páginas iniciales, una lenta discusión en las intermedias, una solución en las últimas. Ya aclarado el enigma, hay un párrafo largo y retrospectivo que contiene esta frase: Todos creyeron que el encuentro de los dos jugadores de ajedrez habia sido casual. Esa frase deja entender que la solución es errónea. El lector, inquieto, revisa los capítulos pertinentes y descubre otra solución, que es la verdadera. El lector de ese libro singular es más perspicaz que el detective(1974, p. 462).

La frase que contiene la clave, en "Tema...", es la comparación con el palco funerario, que bien podría pasar desapercibida para el lector que asiste al final del relato. La mención de Lincoln dialoga además con otras pistas diseminadas en el texto -como la alusión velada a Jesucristo- para sugerir otras líneas de lectura que despliegan la figura del tiempo cíclico con nuevas capas que Ryan no vio (Jesucristo-Julio CésarKilpatrick-Lincoln). ${ }^{12}$ La figura del tema repitiéndose en el tiempo hace pensar a Ryan en Condorcet, Hegel, Spengler, Vico y hasta en Hesíodo; Borges, en cambio, invoca los nombres de Chesterton, Leibniz y Yeats para enmarcar su tema. ${ }^{13}$ El lector que vuelva al comienzo del cuento alentado por estos indicios, encontrará que tanto el epígrafe como las palabras introductorias del narrador sugieren otra lectura y otra concepción del universo: el tema del traidor y del héroe es, en realidad, el de un arquetipo que se repite con variaciones en el tiempo circular, a lo largo de la Historia; e incluye la relativización del discurso histórico como producto del lenguaje. Esta relectura pone en evidencia que el cuento es un relato enmarcado en el que el narrador siembra a lo largo de la superficie textual una serie de pistas destinadas al lector, que el detective no puede ni siquiera considerar -la mención a la Biblia y al palco de Lincoln son parte del texto que narra a Ryan, al que él no tiene acceso-. El investigador irlandés sirve para exponer una de las tramas del cuento -no todas-, y también para sacar a la luz un enigma central y desestimarlo. ${ }^{14}$ La primera lectura del texto termina con las acciones de 
Ryan -con la decisión espectacular de no publicar la resolución del enigma y escribir un libro previsible sobre el héroe de Irlanda-. La relectura que saca a la luz la serie de repeticiones sugerida en la superficie textual desplaza a Ryan e impulsa al lector a reflexionar sobre el marco del relato, sobre la función del epígrafe y el título del cuento, es decir, sobre las intenciones del narrador principal, esa reproducción discursiva de Borges. El descubrimiento de las alusiones a Jesucristo a través de la utilización de las técnicas de lectura provistas por el cuento, por otro lado, hace que el lector ocupe el lugar de Ryan, haga lo que él hizo, y se sienta, finalmente, interpelado por el texto: es evidente que su lectura también estaba prevista.

\section{UN DISPOSITIVO DE LECTURA}

El lector que haya llegado hasta aquí -interpelado por el texto o por esa figura de Autor que se constituye en otro lugar, completamente distanciada de la del autor romántico que transmite emociones y valores, o dicta cátedra sobre cuestiones morales o ideológicas- puede acometer una relectura de Ficciones como un complejo mecanismo interconectado que lo incita a releer cuidadosamente. En la primera línea del Prólogo, el autor rompe el silencio para recomendar una forma de leer el volumen: "Las siete piezas de este libro no requieren mayor elucidación” (Borges, 1974, p. 429). ${ }^{15}$ El lector curioso reconoce la ironía, la pista falsa, el procedimiento de exhibir lo esperable para ocultar otro nivel de lectura que ya experimentó cuando transitó "Tema del traidor y del héroe". Después de estos ejercicios, puede tomar nota de los procedimientos necesarios para pasar del otro lado del texto, más allá de la superficie:

- Desconfiar del autor y de lo que explícitamente diga sobre un texto.

- Desconfiar de todo lo que el texto dice y explica, de las soluciones que da.

- Leer todo. Todo es relevante, especialmente lo que parece accesorio.

- Releer. El texto no se cierra con el punto final y con la conclusión que ofrece.

- Conectar. Las claves para develar lo que un texto esconde pueden estar en otro.

- Siempre hay otra lectura. Un texto siempre habla de otra cosa y esconde algo.

- Siempre hay otra lectura. Sucesivas relecturas cambian la forma de percibir un texto.

Las instrucciones para una lectura suspicaz seguramente serían del agrado de un crítico formalista como Pezzoni que, cuando mencionaba la potencia didáctica de la obra de Borges, posiblemente pensara en alguna de estas estrategias. ${ }^{16}$ "Tema del traidor y del héroe" puede considerarse como una productiva área de trabajo para el ejercicio de la lectura activa. El lector curioso que se lance a esa tarea, seguirá encontrando nuevos niveles ocultos detrás de la superficie textual, que le permitirán ampliar las redes de sentido que pueden desplegarse a partir del cuento, para visualizar, así, otras zonas de la compleja arquitectura detrás del pequeño relato. ${ }^{17} \mathrm{Si}$ bien las conexiones que discutimos pueden establecerse sin salir de Ficciones, una investigación que se abra a conexiones intertextuales encontrará otras revelaciones sustanciosas.

$\mathrm{Si}$, por ejemplo, se sospecha de la mención de Lincoln -como Balderston hizo con las opciones ofrecidas para situar la trama del tema(2010) - y se sale del cuento para investigar sus aparentemente irrelevantes anclajes históricos, el círculo de repeticiones que se sugiere con la figura del presidente estadounidense se carga de sentido y altera la lectura que teníamos del texto. Los sucesos que rodean la muerte de Lincoln tienen tantas coincidencias con la de Kilpatrick, que podrían ser considerados como parte de la construcción argumental o incluso como origen de "Tema del traidor y del héroe". ${ }^{18}$ Lincoln no sólo era un ávido lector de Macbeth, fascinado por la discusión que la obra plantea sobre la ambición y el poder, sino que deliberadamente representó en su vida parte del drama (Knox Beran, 1998, p. 7). La noche antes del atentado que terminaría con su vida, soñó con una imagen de la muerte que aparece en Macbeth y que solía citar en sus discursos. Para Wilson, la premonición habilita a pensar el asesinato en el teatro desde una perspectiva dramática: "He had foreseen and accepted his doom; he knew it was part of the drama" (1994, p. 129). ${ }^{19} \mathrm{La}$ 
relectura e investigación de lo que parece accesorio, casual, aleatorio en el cuento ilumina partes del relato que permanecían ocultas, lo resignifican, multiplican su trama y modifican tanto la jerarquización de sus partes -lo determinante, lo importante, lo aleatorio- como el régimen de causalidad que el texto expone Ryan soluciona el problema/Ryan se equivoca, las repeticiones son obra de un autor que escribe la Historia/ la Historia repite una serie de arquetipos fijos-.

La puesta en escena de la Biblia como intertexto, el comentario sobre Lincoln, así como las pistas que llevan a multiplicar el tema a lo largo de la Historia hacen evidente que "Tema del traidor y del héroe" no sólo pone en escena la aventura de leer significados ocultos en un texto en el que éstos fueron disimulados por un autor para que en el futuro otro lector pudiera sacarlos a la luz -esa imagen que se repite a lo largo de Ficciones-, sino que también lo incita a poner en práctica esa peripecia. El lector activo que desconfía de los límites estrictos de un cuento que desde el comienzo se presenta como un tema incompleto, detecta la invitación a participar activamente de la serie de duplicaciones, a ser como los personajes del relato, a hacer lo que ellos hicieron, a entrar en el texto o -mejor- a tomar conciencia de que el cuento lo ha absorbido y ahora forma parte de las figuras descritas en él. Detrás de la aparente precariedad del relato que expone un tema no resuelto aún, lo que se revela al lector capaz de manejar estas variables y ordenarlas, es una maquinaria precisa, asombrosamente condensada, saturada de pistas para acceder a otra lectura que permite reproducir la escena privilegiada que circula alrededor del libro, -la de la buena lectura- a la que sólo se llega después de un dedicado entrenamiento para leer lo que no es evidente, para acceder a un hecho literario que requiere del trabajo activo, de la relectura, de la suspicacia y la complicidad. Un arte desacralizado, propio de contrabandistas y falsificadores, que Ficciones expone, recomienda y, finalmente, permite poner en práctica.

\section{REFERENCIAS}

Balderston, D. (2010). 'Digamos Irlanda, digamos 1824': para repensar la historia en Borges. En Innumerables relaciones: cómo leer con Borges. Santa Fe, Argentina: Universidad Nacional del Litoral, 102-118.

Balderston, D. (2011). The Rag-and-Bone Shop: On Borges, Yeats and Ireland. Variaciones Borges, 32, 41-58.

Borges, J. L. (1974). Obras completas. Buenos Aires, Argentina: Emecé.

Borges, J. L. (2016). M. E. Vázquez. Los nombres de la muerte. En Prólogos, con un prólogo de prólogos; Borges oral. Buenos Aires, Sudamericana, 233-236.

Louis, A. (Ed.), (1999). Enrique Pezzoni lector de Borges. Lecciones de literatura 1984-1988. Buenos Aires, Argentina: Sudamericana.

Knox Beran, M. (1998). Lincoln, Macbeth and the Moral Imagination. Humanitas, XI(2), 4-21.

Ludmer, J. (2000). ¿Cómo salir de Borges? En W. Rowe, C. Canaparo y A. Louis (Ed.), Jorge Luis Borges. Intervenciones sobre pensamiento y literatura. Buenos Aires, Argentina: Paidós, 289-300.

Panesi, J. (2018). Las políticas de Borges. En La seducción de los relatos. Crítica literaria y politica en Argentina. Buenos Aires, Argentina: Eterna Cadencia, 297-319.

Parodi, C. (1999). Borges y la subversión del modelo policial. En R. Olea Franco (Ed.), Borges: desesperaciones aparentes y consuelos secretos. México: El colegio de México, 77-97.

Pauls, A. (2010). La herencia Borges. Variaciones Borges, 29, 177-188.

Pauls, A. (2007). El factor Borges. Barcelona, España: Anagrama.

Tomashevski, B. (1978). Temática. En T. Todorov (Ed.), Teoría de la literatura de los formalistas rusos. Buenos Aires, Argentina: Siglo XXI, 199-232.

Wilson, E. (1994). Patriotic Gore: Studies in the Literature of the American Civil War. New York, Estados Unidos: W. W. Norton and Co. 


\section{Notas}

1 La gravitación de la Obra es tan poderosa que Josefina Ludmer titula un artículo “¿Cómo salir de Borges?”, como si se tratara de un espacio totalizador, omnipresente, que encierra a la crítica y la literatura argentinas, y plantea la posibilidad de “salir de Borges con Borges', desde adentro" (2000: 289). En una valoración también extrema, Pauls señala que "no hay un afuera de Borges" y que lo que enfurece a sus detractores es "el hecho absolutamente radical de haberlo pensado todo" (2010, p. 181). No se trata de una retórica propia de la crítica literaria argentina: ningún otro autor concita juicios tan absolutos.

2 "Para averiguar qué hay en el texto de Borges tal vez sirva pensar en la pregunta que nos hacemos después de leerlo. Y esa pregunta no es: ¿qué quiere decir?, sino: ¿quépasó? Es decir: la misma pregunta que nos hacemos después de un milagro, un cataclismo, un desmayo" (Pauls, 2007, p. 145).

3 Es el lector con el que fantasean Bioy y el narrador de "Tlön, Uqbar, Orbis Tertius", es el narrador-detective imaginado en "Tema del traidor y del héroe", es Albert en "El jardín de senderos que se bifurcan”, es el que busca la obra de Herbert Quain, y es Lönrot -que con su exitosa capacidad lectora que lo lleva a una trampa mortal, exhibe los límites de este modelo en "La muerte y la brújula"\#, entre otros.

4 Parodi subraya el giro metaliterario del género policial, que pone en evidencia -y también en cuestión- categorías como lector, autor, narrador, personaje y trama, frente a la literatura realista que exige lo contrario, la suspensión de la incredulidad (1999, p. 82-83). Borges complicaría el modelo del policial para generar un "espacio ideal para dar forma narrativa a cuestiones filosóficas y textuales que afectan el argumento y la morfología del relato” y desplegar así, en lugar de la certeza, "la conjetura, la perplejidad, la paradoja" (1999, p. 84).

5 En este sentido, Pauls expone las metas del proyecto literario del joven Borges, que se desentiende conscientemente de la originalidad literaria para buscar un lector activo y curioso que quiera ir más allá de la primera lectura: "Ya [entre mediados de los años veinte y 1930] no piensa en escribir algo por primera vez, algo que nadie haya escrito antes, sino algo que pueda ser leído dos veces" (2007, p. 18).

6 La relectura le recuerda al lector curioso que lo que acaba de leer no es un cuento terminado sino un tema que un narrador identificado con Borges ha planteado como inconcluso. Los personajes, así, se vuelven menos históricos y más abstractos, ya que funcionarían como actantes que llevan adelante una trama, el tema que se quiere contar, más allá de su inscripción espacial y temporal. Sin embargo, una lectura suspicaz descubrirá que esto también es falso, y que ni la elección de Irlanda ni las otras opciones de países oprimidos y tenaces son casuales: detrás de la enumeración y la elección aparentemente banal, hay una potente causalidad que le da al cuento un significativo anclaje histórico (véase Balderston, 2014, pp. 104-110).

7 Esta certidumbre condensa una estrategia lectora del formalismo ruso y del estructuralismo: el crítico deja de lado los anclajes históricos, las referencias a un contexto determinado y la representación del mundo, para dedicarse al análisis inmanente del texto. La certeza de que un texto habla secretamente sobre sí mismo es, también, una vuelta de tuerca del pacto de lectura del género policial como las que operan Borges y, después, Piglia.

8 Borges reescribe “Tema del traidor y del héroe” llevando la categoría de Autor a su sentido más pleno. En “Tres versiones de Judas", el personaje descubre con espanto detrás del enigma invisible en la Biblia, la ominosa figura que codificó el misterio, el Autor: "Valerio Soriano murió por haber divulgado el oculto nombre de Roma; ¿qué infinito castigo sería el suyo, por haber descubierto y divulgado el horrible nombre de Dios?” (1974, p. 517-18)

9 De hecho, el ejemplo canónico que se toma para explicar las técnicas de lectura de los formalistas, es el que cita Tomashevski cuando expone el uso de motivos en un texto: "Chéjov pensaba en la motivación compositiva cuando dijo que si al comienzo del cuento se dice que hay un clavo en la pared, el héroe deberá colgarse de ese clavo al final” (1978, p. 214).

10 Los ecos de la Biblia se logran con frases evidentes que hasta desentonan con la brevedad y contención del resto del cuento: la comparación con Moisés se extiende innecesariamente hasta "la tierra de Moab", Kilpatrick entra en Dublín como si fuera una ciudad antigua amurallada y una vez allí despliega actividades que se corresponden con las de Jesucristo al entrar en Jerusalén y, finalmente, la aislada mención de la violación del sepulcro del héroe irlandés, que remite a la resurrección. Las llamativas referencias recuerdan otra de las máximas de Ficciones: "Omitir siempre una palabra, recurrir a metáforas ineptas y a perífrasis evidentes, es quizá el modo más enfático de indicarla” (Borges, 1974, p. 479).

11 La primera versión del cuento aparece en el número 112 de Sur, en febrero de 1944. En el mismo año, se publica en Ficciones. Borges agrega un párrafo final que explicita la relación que se establece entre el autor y ese lector privilegiado que se siente interpelado por el texto. Reaparece Ryan y al sentir que la mirada de Nolan previó sus pasos, decide ocultar su descubrimiento. Este nuevo final vuelve más intrascendente la mención a Lincoln, que antes formaba parte de la conclusión.

12 A estos círculos se agregan los protagonistas de las tramas alternativas a la irlandesa que señala Balderston a partir de su investigación de las posibles locaciones para el tema, mencionadas por el narrador antes de elegir Irlanda en 1824: “Adam 
Mickiewicz y el padre de Conrad, Garibaldi, el coronel Suárez y Bolívar, el rey Otto", así como los que protagonizarían "la versión peruana o argentina, o paraguaya, o neogranadina, de esta historia" (2010, pp. 116 y 107).

13 Estratégicamente, Borges cita un poema de Yeats - "1919"- por el nombre del libro que lo contiene - The Tower-, que genera una larga serie de relaciones; la más inmediata, con la torre de Kilgarvan con la que sueña Kilpatrick. Para ahondar en el uso significativo de Yeats para introducir la lógica del tiempo circular en el cuento, veáse Balderston (2011).

$14 \mathrm{La}$ circularidad del tiempo y los arquetipos que repiten unos temas básicos a lo largo de la Historia recorren la Obra de Borges. En este sentido "Tema..." está conectado a través de los epígrafes de Yeats con "Biografía de Tadeo Isidoro Cruz" (Balderston, 2011, p. 47-49).

15 Con "siete piezas" se refiere a las que integran el apartado El jardín de senderos que se bifurcan, publicado en 1941. En la edición de Ficciones de 1944, Borges agrega los cuentos de Artificios, que también incluye un prólogo que confirma la sentencia que abre el volumen: "Aunque de ejecución menos torpe, las piezas de este libro no difieren de las que forman el anterior" (Borges 1974, p. 483).

16 El potencial didáctico de la Obra excede en mucho los límites de una investigación como esta. Nos limitamos a considerar un cuento en el económico marco del libro que lo contiene.

17 Dejamos de lado en estas consideraciones todos los usos que pueden hacerse del cuento para ilustrar símbolos o narrativas ajenos a él. Estamos desplegando conexiones que de ninguna manera pueden atribuirse a una operación inconsciente del autor, sino que fueron deliberadamente incluidas en la arquitectura del texto para habilitar mecanismos que abren otros niveles de lectura.

18 La mención del palco como pista sigue, como es de esperarse, la estrategia de Nolan para citar a Shakespeare: es una de las partes menos relevantes, menos dramáticas, en el paralelismo entre los dos asesinatos.

19 Wilson describe los pasos de Lincoln yendo dramáticamente al muere, y sus palabras sirven para los de Kilpatrick, Julio César y Jesucristo.

\section{BY-NC-SA}

